\title{
The role of surgery in the management of women with gestational trophoblastic disease
}

\section{Papel da cirurgia no manejo de mulheres com doença trofoblástica gestacional}

Lana de lourdes Aguiar Lima ${ }^{1,2}$; Lílian Padron ${ }^{1,3}$; Raphael Câmara ${ }^{1,4}$; Sue Yazaki Sun ${ }^{5}$; Jorge Rezende Filho, TCBC-RJ1,2; Antônio BRAGA $^{1,2,3}$.

\section{A B S T R A C T}

\begin{abstract}
The Gestational Trophoblastic Disease includes an interrelated group of diseases originating from placental tissue, with distinct behaviors concerning local invasion and metastasis. The high sensitivity of the serial dosages of human chorionic gonadotrophin, combined with advances in chemotherapy treatment, have made gestational trophoblastic neoplasia curable, most often through chemotherapy. However, surgery remains of major importance in the management of patients with gestational trophoblastic disease, improving their prognosis. Surgery is necessary in the control of the disease's complications, such as hemorrhage, and in cases of resistant/relapsed neoplasia. This review discusses the indications and the role of surgical interventions in the management of women with molar pregnancy and gestational trophoblastic neoplasia.
\end{abstract}

Keywords: Gestational Trophoblastic Disease. General Surgery. Hysterectomy. Thoracotomy. Craniotomy.

\section{INTRODUCTION}

G estational trophoblastic disease (GDT) comprises a group of tumors derived from placental tissue, including benign lesions, represented by the complete and partial hydatidiform mole, and a group of lesions with different degrees of invasion and dissemination, called gestational trophoblastic neoplasia (GTN): Invasive molar disease, choriocarcinoma, placental trophoblastic tumor and epithelioid trophoblastic tumor ${ }^{1}$.

GTD has a variable global incidence, being five to ten times more frequent in Latin America and Asia than in North America and Europe ${ }^{2,3}$. In the United States, about 120 cases are reported per 100,000 pregnancies, while in Brazil, about 460 cases occur in 100,000 gestations $s^{4,5}$.

As a result of the introduction of effective and individualized chemotherapy from prognostic factors, and thanks to the ability to monitor treatment response by monitoring human chorionic gonadotrophin (hCG) levels - a tumor marker -, GTN became a highly curable disease ${ }^{1}$. However, even with advances in the treatment of GTD, there are still surgical indications for the patients affected by this disease, ranging from techniques of uterine evacuation to the management of chemoresistant or relapsed neoplasia and its complications. Discussing them, emphasizing operative tactics, is the purpose of this review.

\section{METHODS}

We performed a search on three databases (Medline, Scielo and Lilacs) using the following keywords: gestational trophoblastic disease, surgery, hysterectomy, thoracotomy, and craniotomy. We limited the search to human studies published in English, Portuguese, Spanish and French from 1966 to 2015. We also used the bibliographic references of articles selected for reading.

\section{Surgical indications for patients with molar pregnancy} Uterine evacuation

All patients with suspected molar gestation, confirmed by ultrasonography, should be sent to centers of reference in the treatment of this disease, where they

1 - Federal University of Rio de Janeiro, Center for Trofoblastic Disease of the Maternity School, Rio de Janeiro, Rio de Janeiro State, Brazil. 2 - Federal University of Rio de Janeiro, Post-Graduate Program in Perinatal Health of the Maternity School, Rio de Janeiro, Rio de Janeiro State, Brazil 3 - Fluminense Federal University, Post-Graduate Program in Medical Sciences, Niterói, Rio de Janeiro State, Brazil. 4 - Federal University of Rio de Janeiro, Institute of Gynecology, Rio de Janeiro, Rio de Janeiro State, Brazil. 5 - Paulista School of Medicine, Federal University of São Paulo, Center for Trophoblastic Diseases of the São Paulo Hospital, Sao Paulo, Sao Paulo State, Brazil. 
will be submitted to uterine emptying of the hydatidiform mole. Studies have shown that there is greater survival and absence of sequelae in patients treated by specialized services ${ }^{4}$.

\section{Preoperative care}

Blood and Rh factor, hematocrit/hemoglobin and platelet levels, plasma hCG titration, liver function (AST, ALT, total bilirubin and fractions) and renal functiontests (Urea, creatinine and uric acid) should be requested in the preoperative period of uterine evacuation of patients with molar pregnancy 5 . In patients with a uterine fundus greater than $16 \mathrm{~cm}, \mathrm{TSH}$, free $\mathrm{T} 4$, and electrocardiogram dosages should also be ordered. Reserve of red blood cell concentrates is prudent in all cases ${ }^{5}$.

Pelvic-transvaginal ultrasonography should be performed for uterine evaluation (confirmation of diagnostic suspicion) and adnexal evaluation (search for any tea- luteinic cysts). This exam should be complemented with Doppler of the uterine arteries, a prognostic marker of the disease evolution. Chest radiography should be requested not only to serve as a base exam, since the lungs are the main site of metastasis, but also to evaluate cases of trophoblast embolization ${ }^{5}$.

\section{Uterine evacuation techniques}

The use of medications such as oxytocics and prostaglandin analogues produce contractions of the uterine musculature, which, by raising the intracavitary pressure, may cause embolization of trophoblastic tissue and should not be used ${ }^{6}$. In the specific cases of partial hydatidiform mole with fetal presence, cautious use of drug agents becomes necessary for tissue expulsion? Since hysterotomy renders important morbidity, due both to allowing the passage of trophoblastic tissue into the circulation, raising the risk of post-molar GTN, and to compromising the reproductive future, it is a proscribed technique ${ }^{8}$.

Uterine vacuum aspiration is the procedure of choice for the uterine evacuation of patients with molar pregnancy, because it is safe, fast and effective (Figure 1). It can be performed by electrical aspiration or by intrauterine manual aspiration. For this, the cervical

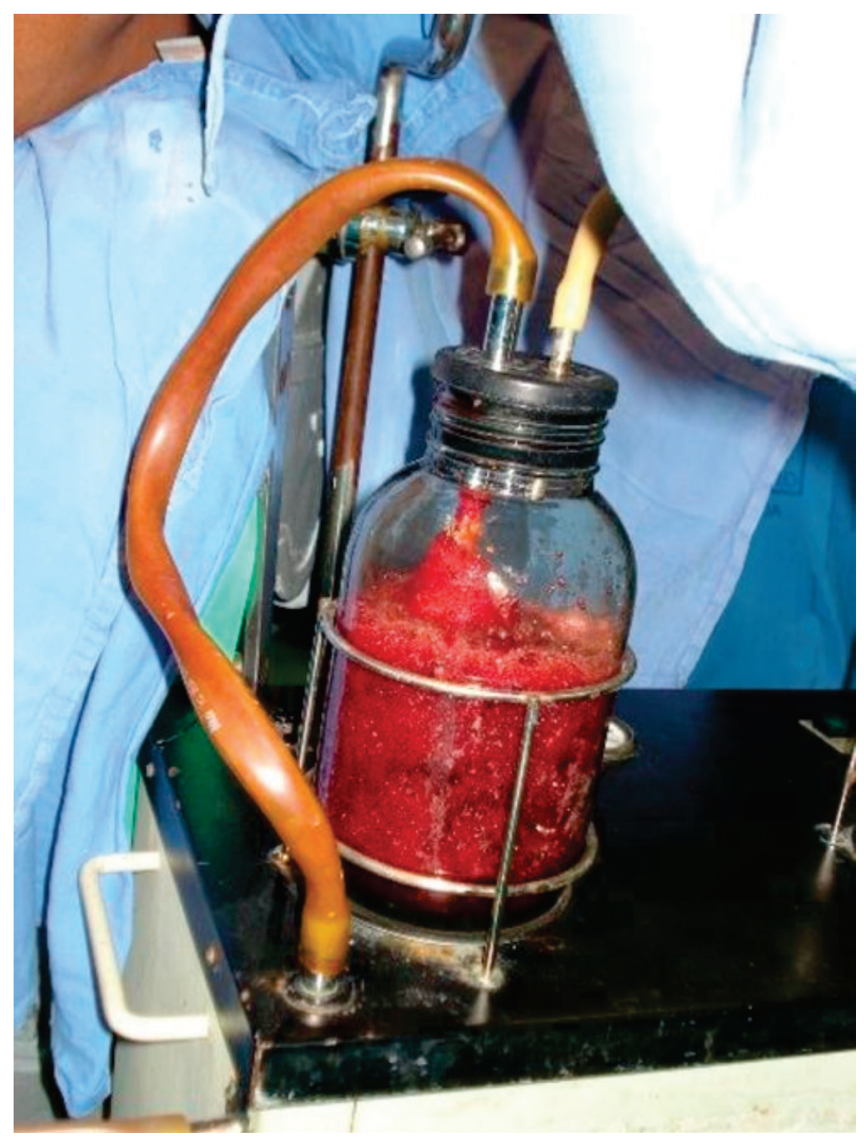

Figure 1. Uterine aspiration (electric).

dilation is performed with dilators, with later introduction of the cannula into the uterine cavity. Large amounts of molar material are aspirated with rotational movements of the instrument. The aspirate is completed with discrete movements with the cannula, simulating the classic curettage movements ${ }^{6}$. One should avoid the use of oxytocin, restricted to the end of the procedure or in cases of copious hemorrhage, due to the imminent risk of trophoblastic embolization. Intraoperative ultrasonography is very useful because it allows the location of the cannula, minimizing the risk of uterine perforation, and confirming complete emptying ${ }^{9}$.

It is known that the uterine volume shows direct correlation with the risk of complications, among them perforation, hemorrhage, infection and pulmonary complications. In uterine volumes less than $16 \mathrm{~cm}$, the occurrence of such complications is rare ${ }^{10}$. Mungan et al. ${ }^{11}$ found a $0.6 \%$ uterine perforation rate in 310 patients. If a perforation occurs, the procedure must be interrupted and the lesion site can be identified by laparoscopy (or 
Table 1. FIGO 2000 risk score system.

\begin{tabular}{lcccc}
\hline \multicolumn{1}{c}{ FIGO Score } & 0 & 1 & 2 & 4 \\
\hline Previous pregnancies & Mole & Abortion & Term & - \\
Gestation interval (months) & $<4$ & $4-6$ & $7-12$ & $>12$ \\
Pre-treatment B-hCG (mIU/mL) & $<10^{3}$ & $10^{3}-10^{4}$ & $10^{4}-10^{5}$ & $>^{5}$ \\
Greatest extent of tumor including uterus (cm) & $>3$ & $3-5$ & $>5$ & - \\
Site of metastasis & Lung & Spleen/Kidney & GIS* & Liver/Brain \\
Number of metastasis & 0 & $1-4$ & $5-8$ & $>8$ \\
Previous chemotherapy & - & - & 1 drug & $\geq 2$ drugs \\
\hline
\end{tabular}

The total score is obtained by summing the individual points for each prognostic factor. Low risk, 0-6; high risk $\geq 7$. The Placental Trophoblastic tumor and Epithelioid Trophoblastic Tumor should not be evaluated by this method.

GIS - gastrointestinal system.

Source: FIGO Oncology Commitee (2003).

by laparotomy if this technique is not available). In the absence of damage to other structures, uterine emptying is finished under direct vision, with subsequent synthesis of the perforation9. In cases of hemostatic difficulty, management should be individualized and hysterectomy may become a therapeutic option.

Pulmonary complications are also likely to occur when emptying large uteri. Twiggs et al. ${ }^{12}$ found $27 \%$ of complications among patients with uterine volumes greater than $16 \mathrm{~cm}$. Trophoblastic embolization, preeclampsia, anemia, water intoxication and hyperthyroidism are cited as responsible for the majority of cases of pulmonary involvement ${ }^{9}$.

Prophylactic hysterectomy may be an option to uterine evacuation for patients with established offspring and advanced maternal age. It reduces the risk of progression to GTN from $20 \%$ to $3.5 \%$ when compared with vacuum aspiration ${ }^{13}$. Elias et al. ${ }^{14}$ did not find any case of evolution to neoplasia in patients treated with prophylactic hysterectomy over 40 years. However, although the prophylactic hysterectomy eliminates the risk of local invasion, it does not exclude the possibility of metastatic GTN. For this reason, it is important that all patients perform post-molar follow-up with serial hCG.

\section{Second uterine emptying}

The efficacy of the second uterine evacuation is unclear. Studies have shown that only a limited number of patients with low-risk GTN (Table 1$)^{15}$ benefit from this approach ${ }^{10}$. Van Trommel et al. ${ }^{16}$ reported that only eight (9.4\%) out of 85 patients who underwent a second emptying did not need chemotherapy compared with none in the control group (209 patients). They also identified an effect of tumor load reduction in this study, with the intervention group requiring on average one chemotherapy cycle less than the control group. In the United Kingdom, the second uterine evacuation is considered only in cases where ultrasound suggests disease confined to the uterine cavity and hCG levels below 5000IU/L ${ }^{17}$.

\section{Surgical indications for patients with GTN}

Hysterectomy as primary GTN treatment

Chemotherapy is considered the first-line treatment for patients with GTN who wish to maintain fertility. The remission rate in patients with nonmetastatic or low-risk GTN is nearly $100 \%$. However, the adjuvant surgical procedure has the power to reduce the length of hospital stay and the number of chemotherapy cycles and, therefore, is reported as an option in cases of disease confined to the uterus and absence of reproductive desire (Figure 2). It is usually associated with exploration of the entire abdominal cavity. However, the vaginal route can also be performed without major complications $^{18}$. Cagayan and Magallanes $^{19}$ found a 98.4\% survival rate among 129 hysterectomized patients during GTN management. Indications for the procedure were uterine rupture, vaginal bleeding, resistance 


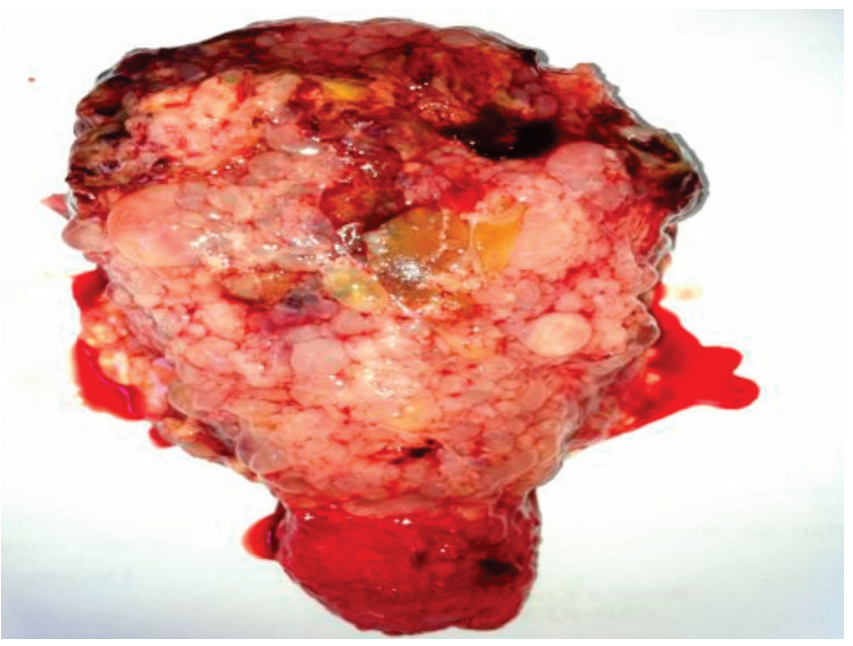

Figure 2. Prophylactic hysterectomy specimen.

to chemotherapy, and adjuvant initial therapy when there was no reproductive desire. In cases of advanced metastatic disease, its indication is controversial, as besides not presenting a curative role, it may increase morbidity. An exception to this is the presence of bulky and hemorrhagic tumor ${ }^{20}$.

\section{Surgery in patients with chemoresistant/relapsing GTN}

Before indicating surgical resection, imaging examinations are performed to document the presence of neoplasia in the uterus or in other localities. They are chest tomography and magnetic nuclear resonance of the skull and pelvis7,9. Most surgical procedures are performed during chemotherapy to minimize the possibility of metastatic induction by tissue manipulation. Studies do not show an increase in morbidity with this therapeutic combination?'

Hysterectomy/Robotics/Local uterine resection by minimally invasive surgery

Hysterectomy is an option for patients who did not respond to the chemotherapy regimen of first and second lines (usually methotrexate and actinomycin-D), especially in those with no reproductive desire. Ghaemmaghami et al. ${ }^{21}$ reported an incidence of $17.6 \%$ of hysterectomies in patients with chemoresistant GTN. Several studies have shown that uterine excision is effective in producing remission in most patients and those who did not benefit probably had occult metastatic neoplasia?.
Most hysterectomies are performed by the abdominal route. The vaginal route can be considered in women without metastatic neoplasia, with small volume uteri and low hCG levels, but the evaluation of the upper abdomen in search of hidden metastasis becomes impossible1. The laparoscopic route has well documented advantages, including less complications and shorter hospital stay. Riley et al. ${ }^{22}$ documented the first roboticassisted hysterectomy in a patient with GTN in 2015. After surgery, she received five cycles of mono-chemotherapy with actinomycin $\mathrm{D}$. The patient achieved normalization of hCG levels at the fourth postoperative week.

Resection of local uterine lesion with reconstruction may be considered an option in patients without metastatic disease and with a desire to maintain fertility. There is a report of a patient with chemotherapyresistant GTN treated with uterine segmental resection followed by hysteroplasty. She had two successful pregnancies after treatment ${ }^{23}$. The lesion should be carefully located by a combination of imaging tests: magnetic resonance imaging, Doppler ultrasonography and/or hysteroscopy. Lesions smaller than $2 \mathrm{~cm}$ in diameter associated with low hCG levels are more likely to be completely resected ${ }^{20}$.

\section{Pulmonary resection}

It is the most performed procedure to eliminate extrauterine metastatic neoplasia. Pulmonary metastasis occurs in up to $70 \%$ of patients with GTN, and $90 \%$ of these are cured with chemotherapy. Treatment failure has been attributed to an ineffective concentration of the drug that reaches the lesion, due to central necrosis or tumor incarceration by fibrin'. There are several cases of GTN detection only after the histopathological result of a resected lung lesion without previous diagnosis ${ }^{9}$.

Several reference centers have published satisfactory results with nodulectomy and lobectomy in the management of patients at high risk for GTN (Table $1)^{15}$. A single, unilateral lesion associated with low levels of hCG has encouraging results 9 .

Tomada et al. ${ }^{24}$ proposed five criteria to obtain therapeutic success with surgery: patient with good surgical status; controlled primary uterine tumor; absence 


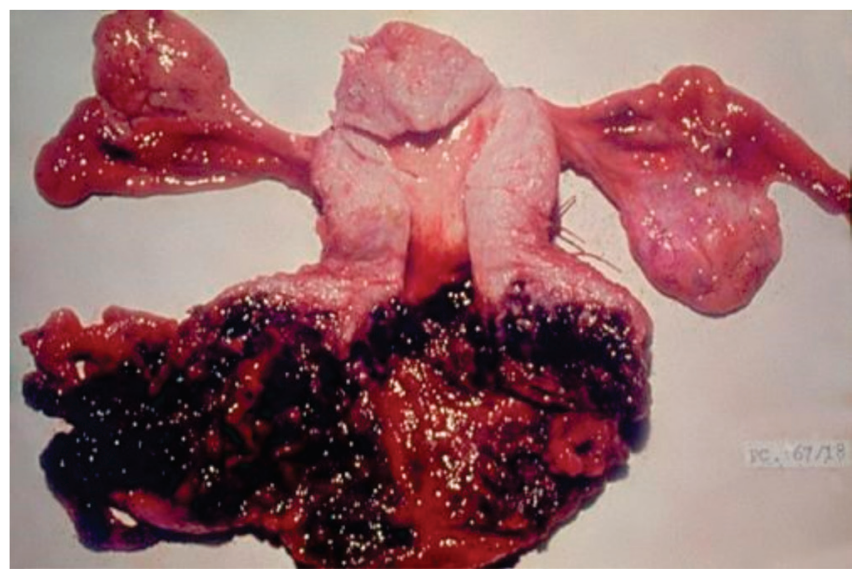

Figure 3. PTT with extensive vaginal metastasis.

of other sites of metastasis; solitary lung injury; and hCG level $<1000 \mathrm{mIU} / \mathrm{mL}$. They also reported that 14 out of 15 patients who fulfilled all the criteria were cured with the procedure, compared with no case among patients with a score greater than or equal to 1 . Eoh et al. ${ }^{25}$, in 2015, reported complete remission in the three cases that underwent pulmonary resection due to persistent disease.

Several research centers have demonstrated that the occurrence of expressive regression of hCG levels within one to two weeks of surgical resection predicts a favorable outcome ${ }^{20}$.

\section{Craniotomy}

Brain metastases occur in $8-15 \%$ of patients with GTN and the treatment is based initially on the association of radiation therapy with chemotherapy, to prevent hemorrhage, neurological deterioration and death. In cases of increased intracranial pressure, craniotomy is indicated for CNS decompression and stabilization ${ }^{9}$. Another indication is the excision, in rare cases, of isolated nodules resistant to drug treatment. This therapeutic regimen results in rates of $65 \%$ to $80 \%$ of primary remission and up to $90 \%$ cure $^{20}$.

The timing of perioperative chemotherapy is likely to play a role in the prevention of late metastases. Patients who underwent chemotherapy within one week of craniotomy became less likely to present recurrence compared with those who received chemotherapy more than one week after surgery ${ }^{25}$.

\section{Clinical predictors of surgical response in patients with chemoresistant GTN}

The identification of surgical response predictors in patients with persistent GTN is a field that remains under investigation. Feng et al. ${ }^{26}$ showed that several preoperative factors were significantly different between the group with therapeutic success and the group that presented failure. These factors included age greater than 35 years, history of non-molar gestation, metastases in locations beyond the uterus and lungs, and pre-surgical levels of hCG. Patients older than 35 years or pre-surgical levels of hCG greater than $10 \mathrm{mIU} /$ $\mathrm{mL}$ have a near $50 \%$ chance of treatment failure. No patient with two or more unfavorable factors evolved for cure.

Several studies have shown that the level of hCG before surgery is an important predictor of the therapeutic response and should be maintained low. Tomada et al. ${ }^{24}$ found survival improvement in patients with levels below $1000 \mathrm{mlU} / \mathrm{mL}$.

There is a correlation between metastatic sites and surgical response. The presence of other foci other than the uterine and pulmonary ones is a poor prognostic factor. However, Wang et al. ${ }^{27}$ reported the survival of five out of seven patients who had more than one metastatic site and underwent pulmonary resection.

The FIGO prognostic score did not prove to be a good predictor of surgical treatment and was considered inadequate for the evaluation of chemoresistant patients ${ }^{26}$.

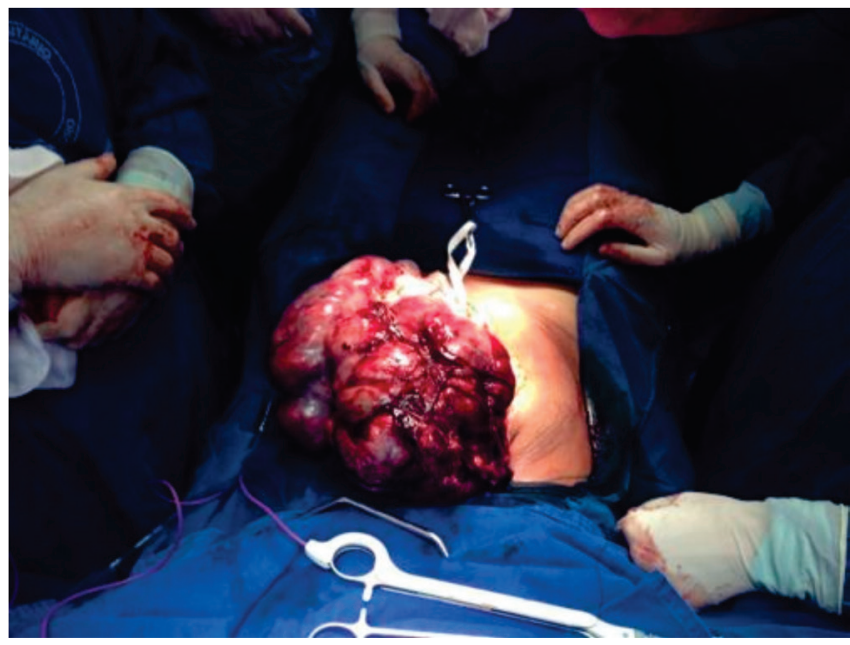

Figure 4. ETT in patient with large abdomino-pelvic mass. 
Table 2. Staging system for GTN- FIGO 2000.

\begin{tabular}{ll}
\hline Stage I & Disease confined to the uterus. \\
Stage II & GTN spread out of the womb, but limited to the genital system. \\
Stage III & GTN spread to the lungs, with or without involvement of the genital system. \\
Stage IV & All other sites of metastasis. \\
\hline
\end{tabular}

Source: FIGO Oncology Commitee (2003)

\section{Treatment of special forms of GTN}

The placental trophoblastic tumor (PTT) and the epithelioid trophoblastic tumor (ETT) are the rarest forms of GTN, with biological behavior different from the others. They present with low levels of hCG, slow growth, metastases months or years after the gestation, and are resistant to polychemotherapy ${ }^{28}$.

\section{Placental trophoblastic tumor (PTT)}

Its incidence is $1: 100,000$ pregnancies, accounting for $1 \%$ to $2 \%$ of GTN cases $^{28}$. The primary treatment for this group of tumors is total hysterectomy, with pelvic and retroperitoneal lymph node sampling, especially for women with localized disease and complete offspring (Figure 3 ). In patients with reproductive desire, there are reports of good results with non-sterilizing procedures. Saso et al. ${ }^{29}$ published a case of PTT treated with free-margin resection of the uterine lesion and organ reconstruction (modified Strassman's surgery). After the procedure, the patient had two miscarriages and one term gestation with a healthy fetus. The prognosis is favorable when the disease is limited to the uterus. In the presence of metastatic disease, the mortality rate may reach $25 \%$. Schmid et al. ${ }^{28}$ showed that the combination of surgery with chemotherapy in stages II, III, IV (Table 2) ${ }^{15}$ improves outcomes.

\section{Epithelioid trophoblastic tumor (ETT)}

ETT accounts for less than $2 \%$ of all GTN cases (Figure 4). They are present in women with full term gestation with one to 18 years interval after pregnancy ${ }^{30}$. Metastatic neoplasm associated with an interval greater than four years from the previous gestation is considered a worse prognostic factor ${ }^{28,30}$. Surgical resection is the pillar of the treatment. Hysterectomy should be indicated in patients with disease confined to the uterus to maximize the cure opportunity. Davis et al. ${ }^{30}$ reported that several surgical procedures are frequently required in patients with ETT, particularly in those with extrauterine disease.

\section{CONCLUSION}

Molar gestation should be treated with uterine vacuum aspiration, avoiding techniques such as hysterotomy and drug inductions. Although chemotherapy continues as the central point of management of patients with GTN, surgery, when correctly indicated, plays a significant role in increasing cure rates. Approximately half of patients with high-risk GTN require surgery during treatment, both to achieve remission and to treat complications. Although the literature shows improved therapeutic success rates, the management of chemoresistant patients is still a challenge. Higher cure rates are expected when patients are treated at referral centers.

\section{R E S U M O}

Doença trofoblástica gestacional inclui um grupo interrelacionado de doenças originadas do tecido placentário, com tendências distintas de invasão local e metástase. A alta sensibilidade das dosagens seriadas de gonadotrofina coriônica humana aliada aos avanços do tratamento quimioterápico tornou a neoplasia trofoblástica gestacional, curável, na maioria das vezes, através da quimioterapia. No entanto, a cirurgia permanece ainda, da maior importância na condução de pacientes com doença trofoblástica gestacional, melhorando seu prognóstico. A cirurgia é necessária no controle de complicações da doença, tais como hemorragia, e em casos de neoplasia resistente/ recidivada. Esta revisão discute as indicações e o papel das intervenções cirúrgicas durante o manejo de mulheres com gravidez molar e neoplasia trofoblástica gestacional.

Descritores: Doença Trofoblástica Gestacional. Cirurgia Geral. Histerectomia. Toracotomia. Craniotomia. 


\section{REFERENCES}

1. Feng F, Xiang Y. Surgical management of chemotherapy-resistant gestational trophoblastic neoplasia. Expert Rev Anticancer Ther. 2010;10(1):71-80.

2. Altieri A, Franceschi S, Ferlay J, Smith J, La Vecchia C. Epidemiology and aetiology of gestational trophoblastic disease. Lancet Oncol. 2003;4(11):670-8.

3. Rincón AE, Torres RM, Torres CO, Avila CE, Martínez $\mathrm{HV}$. Incidencia de enfermedad trofoblástica gestacional detectada por el estudio histopatológico rutinario de los especímenes obtenidos de abortos. Ginecol Obstet Mex. 2008;76(2):81-7.

4. Kohorn El. Worlwide survey of the results of treating gestational trophoblastic disease. J Reprod Med. 2014;59(3-4):145-53.

5. Braga A, Obeica B, Moraes V, Silva EP, Amim Junior $J$, Rezende Filho J. Doença trofoblástica gestacional atualização. Rev HUPE. 2014;13(3):55-61.

6. Schlaerth JB, Morrow CP, Montz FJ, d'Ablaing G. Initial management of hydatidiform mole. Am J Obstet Gynecol. 1988;158(6 Pt 1):1299-306.

7. Tidy J. The role of surgery in the management of gestational trophoblastic disease. In: Hancock BW, Newlands ES, Berkowitz RS, Cole LA, editors. Gestational Trophoblastic Diseases. 3rd ed. London: International Society for the Study of Trophoblastic Disease; 2009. p. 430-46.

8. Tow $\mathrm{W}$. The place of hysterotomy in the treatment of hydatidiform mole. Aust N Z J Obstet Gynaecol. 1967;7(2):97-8.

9. Doll KM, Soper JT. The role of surgery in the management of gestational trophoblastic neoplasia. Obstet Gynecol Surv. 2013;68(7):533-42.

10. Ozalp SS, Oge T. Surgical management in gestational trophoblastic diseases. J Turk Soc Obstet Gynecol. 2012;9(3):133-41.

11. Mungan T, Kuşçu E, Dabakoḡlu T, Senöz S, Uḡur M, Cobanoglu O. Hydatidiform mole: clinical analysis of 310 patients. Int J Gynaecol Obstet. 1996;52(3):233-6.

12. Twiggs LB, Morrow CP, Schlaerth JB. Acute pulmonary complications of molar pregnancy. Am J Obstet Gynecol. 1979;135(2):189-94.
13. Tsukamoto $N$, Iwasaka $T$, Kashimura $Y$, Uchino $H$, Kashimura M, Matsuyama T. Gestational trophoblastic disease in women aged 50 or more. Gynecol Oncol. 1985;20(1):53-61.

14. Elias KM, Shoni M, Bernstein M, Goldstein DP, Berkowitz RS. Complete hydatidiform mole in women aged 40 to 49 years. J Reprod Med. 2012;57(56):254-8.

15. FIGO Oncology Committee. FIGO staging for gestational trophoblastic neoplasia 2000. FIGO Oncology Committee. Int J Gynaecol Obstet. 2002;77(3):285-7.

16. van Trommel NE, Thomas CM, Massuger LF, Sweep FC. Second curettage in persistent trophoblastic disease (PTD): the need for univocal definition of PTD. Gynecol Oncol. 2005;99(1):250-1; author reply 251.

17. McGrath S, Short D, Harvey R, Schmid P, Savage PM, Seckl MJ. The management and outcome of women with post-hydatidiform mole 'low-risk' gestational trophoblastic neoplasia, but hCG levels in excess of 100.000 IU/I(-1). Br J Cancer. 2010;102(5):810-4.

18. Clark RM, Nevadunsky NS, Ghosh S, Goldstein DP, Berkowitz RS. The evolving role of hysterectomy in gestational trophoblastic neoplasia at the New England Trophoblastic Disease Center. J Reprod Med. 2010;55(5-6):194-8.

19. Cagayan MS, Magallanes MS. The role of adjuvant surgery in the management of gestational trophoblastic neoplasia. J Reprod Med. 2008;53(7):513-8.

20. Lurain JR, Singh DK, Schink JC. Role of surgery in the management of high-risk gestational trophoblastic neoplasia. J Reprod Med. 2006;51(10):773-6.

21. Ghaemmaghami F, Ashrafgangooei T, Gillani MM, Mosavi A, Behtash N. Major surgeries performed for gestational trophoblastic neoplasms in a teaching hospital in Tehran, Iran. J Gynecol Oncol. 2011;22(2):97-102.

22. Riley K, Newell J, Zaino R, Kesterson J. Robotic-assisted laparoscopic management of chemoresistant myoinvasive complete molar pregnancy. J Minim Invasive Gynecol. 2015;22(6):1100-3.

23. Case AM, Wilson S, Colgan TJ, Greeblatt EM. Fertility-sparing surgery, with subsequent pregnancy, in 
persistent gestational trophoblastic neoplasia: case report. Hum Reprod. 2001;16(2):360-4.

24. Tomada Y, Arii Y, Kasecki S, Asai Y, Gotoh S, Suzuki $T$, et al. Surgical indications for resection in pulmonary metastasis of choriocarcinoma. Cancer. 1980;46(12):2723-30.

25. Eoh KJ, Chung YS, Yim GW, Nam EJ, Kim S, Kim $\mathrm{SW}$, et al. Role of surgical therapy in the management of gestational trophoblastic neoplasia. Obstet Gynecol Sci. 2015;58(4):227-83.

26. Feng $F$, Xiang $Y$, Li L, Wan $X$, Yang $X$. Clinical parameters predicting therapeutic response to surgical management in patients with chemotherapy-resistant gestational trophoblastic neoplasia. Gynecol Oncol. 2009;113(3):312-5.

27. Wang YA, Song HZ, Xia ZF, Sun CF. Drug resistant pulmonary choriocarcinoma metastasis treated by lobectomy: report of 29 cases. Chin Med J. 1980;93(11):758-66.

28. Schmid P, Nagai $Y$, Agarwal $R$, Hancock B, Savage PM, Sebire NJ, et al. Prognostic markers and logterm outcome of placental-site trophoblastic tu- mours: a retrospective observational study. Lancet. 2009;374(9683):48-55.

29. Saso S, Chatterjee J, Yazbek J, Thum Y, Keefe $\mathrm{KW}$, Abdallah $Y$, et al. A case of pregnancy following a modified Strassman procedure applied to treat a placental site trophoblastic tumour. BJOG. 2012;119(13):1665-7.

30. Davis MR, Howitt BE, Quade BJ, Crum CP, Horowitz NS, Goldstein DP, et al. Epithelioid trophoblastic tumor: a single institution case series at the New England Trophoblastic Disease Center. Gynecol Oncol. 2015;137(3):456-61.

Received in: 01/10/2016

Accepted for publication: 09/12/2016

Conflict of interest: none.

Source of funding: none.

\section{Mailing address:}

Lana de Lourdes Aguiar Lima

E-mail: lanalima@hotmail.com raphaelcmparente@hotmail.com 